\title{
Cartografias sensíveis no e pelo Rio Sabará
}

\section{FREDERICO LUIZ MOREIRA}

UNIVERSIDADE FEDERAL DE MINAS GERAIS (UFMG), BELO HORIZONTE/MG, BRASIL

HTTP://ORCID.ORG/OOOO-0OOI-7475-1673

\section{JÚNIA PATRICLA CARDOSO}

GOVERNO DO ESTADO DE MINAS GERAIS, BELO HORIZONTE/MG, BRASIL

HTTPS://ORCID.ORG/OOOO-OOOI-9962-83I3

Boris Kossoy salienta que: "Toda fotografia representa um testemunho de uma criação. Por outro lado, ela representará sempre a criação de um testemunho" (2014: 54). Por meio desse "testemunho", a fotografia inaugurou-se como um instrumento valioso de registro visual de fatos, de relatos, de linguagens simbólicas presentes nos costumes, nos modos de vida, nas práticas culturais, nos fazeres e nas narrativas nascidas a partir de visualidades. Desse modo, a fotografia torna-se uma "[...] contribuição que a imagem traz ao registro etnográfico não se resume, portanto, na valorização da técnica que gera imagens similares ao mundo sensível, mas reside no fato de que essas imagens são produtos de uma experiência humana "(Bittencourt 1998:197).

Nesse quesito, o presente ensaio fotoetnográfico ${ }^{1}$ tem como ponto central trazer ao debate as relações entre a educação das sensibilidades pelas imagens fotográficas e pela memória (Le Goff 1990) e as discussões ambientais em espaços não-escolares. Essa discussão foi originada a partir das experimentações presentes durante a trajetória de duas oficinas fotográficas, realizadas pelos pesquisadores, em dois momentos e lugares distintos na cidade de Sabará, Minas Gerais, no ano de 2017.

A proposta educativa foi utilizada como intervenção no projeto de pesquisa e extensão universitária, ganhador do prêmio do Edital PAEx No01/2017, “Mãe Domingas: educação pelas águas do Rio Sabará" ${ }^{2}$, desenvolvido em parceria pelas instituições: Grupo de Pesquisa Polis e Mnemosine, da Faculdade de Educação (FaE) da Universidade Estadual de Minas Gerais (UEMG); Museu do Ouro/Instituto Brasi-

1 As fotografias 1, 2, 3, 4, 9 e 10 são de autoria de Júnia Cardoso e a de número 5 de autoria de Frederico Moreira. As demais foram feitas pelas senhoras do projeto Mãe Domingas.

2 Coordenado pela Prof. ${ }^{a}$ Dra. Lana Mara de Castro Siman, do PPGE - FaE/UEMG e pela Ma. Isabella Carvalho de Menezes, Técnica em Assuntos Educacionais do Museu do Ouro, Ibram/MinC. 
leiro de Museus (Ibram); Universidade de Laval - Quebec, Canadá, por meio da Professora Dra. Barbara Bader; Escola de Ciência da Informação - Curso de Museologia da Universidade Federal de Minas Gerais, através do Prof. Dr. Jezulino Lúcio Mendes Braga (tendo participado na primeira fase do projeto). Como nos contam suas coordenadoras, Lana Mara de Castro Siman e Isabella Carvalho de Menezes:

Este projeto visou o fortalecimento de relaçôes de pertencimento, de sociabilidades e de sensibilidades com a finalidade de despertar e potencializar o engajamento ecocidadão das participantes, ou seja, a responsabilidade social e coletiva com relação ao uso sustentável da água e à sua preservação como um patrimônio cultural da cidade. Neste sentido, focou na ideia de sensibilizar a população de Sabaráa partir de mulheres ex-lavadeiras. Quem são essas mulheres, onde elas estão, que tipo de relação estabeleceram com o rio-meio-de-vida, com o rio da infância, quando as águas eram limpas e habitadas por peixes? O que pensam diante do estado de degradação atual em que o rio se encontra, o que fazem pelo rio e o que teriam para compartilhar de suas experiências com a novas gerações, que, desde sempre, conheceram o rio poluido? Essas foram algumas questôes que se colocaram. Por meio das ações educativas e culturais propostas, percebemos o engajamento das ex-lavadeiras e o crescente empoderamento observado na participação delas no projeto, na medida em que memórias subterrâneas foram trazidas à tona, sendo ressignificadas e revalorizadas pelo grupo.

Por intermédio de duas oficinas junto às ex-lavadeiras, moradoras da Rua Pereira Vieira (no Centro) e do Bairro Pompéu, no município de Sabará, nossa proposta foi a de tomar como ponto de partida o uso de fotografias, que inicialmente nos serviriam para deflagrar a curiosidade e a sensibilidade dessas senhoras e, a partir disso, desenvolver um exercício de deslocamento do olhar para ver (Barros 1996), apreendendo o Rio Sabará em dois pontos da cidade, como em dois tempos que se fizeram conectar por meio de um clique.

Não tinha máquina! Assim, na época, a gente não tinha máquina. A gente não registrava. Talvez, alguma coisa a gente possa ter, atémais antiga. Mas, mesmo os mais antigos não têm. Só memória mesmo. Eu moro no Pompéu, mas, não sou nascida lá. Lá eram ruas de cascalho, agora são ruas, tem asfalto, quebrado, mas tem. A casa da gente era terra varrida, tudo era completamente diferente de hoje.

Dona Nilza, moradora do Pompéu.

Por meio dessa fala e demais relatos e reflexões prévias sobre as memórias coletivas e individuais das senhoras participantes, atuamos na perspectiva de [re] estabelecer as relações de afeto e vínculo com seus trajetos, histórias e vivências diante das mudanças e permanências do Sabará. Ligando e conectando o rio às suas vidas e tradições, as senhoras, entre 51 e 93 anos, vivenciaram muitas transformações da e na cidade por meio do seu antigo ofício como lavadeiras.

A realização das duas oficinas que margearam o Rio Sabará foi sugerida para que fossem produzidas outras memórias por meio do registro fotográfico, o que originariam mapas afetivos. Essas representações (Chartier 1991) tomariam como ponto de partida o apontamento de locais de vivência, que visitados, como lugares de memória (Nora 1993), provocariam lembranças na construção de outras possíveis narrativas para a história desse rio. Às margens e curvas do rio que as deu sustento, por meio de admirações e pelas lentes das câmeras, as recordações dessas dezesseis mulheres se desdobraram para outros tempos quando o sentido do rio era outro. Enquanto caminhavam por uma ponte dizendo das 
melhores pedras para bater roupas e dos locais zelados, os gestos e movimentos de seu antigo ofício eram descritos. Os relatos iam das plantas que usavam para quarar as roupas até que ficassem completamente brancas às relações tecidas entre o ofício e a vivência: as experiências sensíveis que levaram as lavadeiras a registrar, pela fotografia, não só imagens, mas reminiscências.

É interessante pensarmos no quanto a fotografia pode "revelar" de sentidos para além da aparente imagem visual. Ela pode, por exemplo, efetuar um discurso e destacar as relações entre um tempo e um lugar, entre corpos e culturas. Todavia, a fotografia foca apenas naquilo que almeja apresentar. Desse modo, o que torna um momento ressonante é perceber que quando um sujeito elege um objeto, naquele instante, as lentes da câmera capturam uma expressão, uma gestualidade em que se é possível vincular o indivíduo ao objeto e, mediante a essa ligação, apreender possíveis leituras e traduções dos eventos. Ao fotografar o rio e seu entorno, percebemos os registros de vozes, de formas, de ecos, de relatos em que podemos identificar uma vivência, uma "história visual".

No percurso do Pompéu, pelo leito do Sabará, as senhoras equipadas com câmeras fotográficas capturaram denúncias, registraram histórias e retrataram camadas de tempo, vida e ausências. Os relatos revelaram saudades; desvelando águas, ora claras, ora turvas, diante do tempo e para além de seus quintais. No primeiro ponto, reencontraram ervas e plantas que na infância cercavam seus quintais e jardins: as avencas nos barrancos; as carquejas e os boldos nos jardins (para os chás quando a saúde não vai bem); limoeiros, canas-caianas, jabuticabeiras, pitangueiras, mangueiras e diversas flores, dentre elas os manacás, com seu cheiro adocicado e belas pétalas violetas e brancas. Encontramos a "Maria, fecha a porta" (Mimosa pudica), uma espécie nativa do Brasil, localizada em várias terras tropicais, que ao ser tocada fecha suas folhas e timidamente se encolhe. O movimento da planta ao encolher-se recompôs em todas as ex-lavadeiras presentes a nostalgia das brincadeiras da infância, quando passavam bons tempos apreciando seus movimentos e o verde presente próximo ao rio.

No mesmo impasse sobre a relação de um olhar para o ambiente, em se habitar o mundo e a incorporação mesma dos enlaces entre cultura e história, entre ser e estar no mundo, Tim Ingold (2010) enfatiza a premissa de um não distanciamento humano dos processos biológicos, o que denota, não apenas na ciência atual, em uma adaptação e em uma representação do mundo, mas em refletir sobre e com a história, enquanto possibilidade de experimentação, "compreendida como o movimento pelo qual as pessoas criam os seus ambientes e, portanto, a si mesmas, não é mais do que uma continuação do processo evolucionário" (Ingold 2010:17). É neste quesito que Ingold infere, a partir dos estudos da fenomenologia de Merleau-Ponty, que a compreensão se estabelece a partir da experimentação sensível dos sujeitos com os fenômenos que os cercam.

No centro urbano da cidade, no segundo ponto, e já tendo passado por outros bairros até alcançar as beiras do Pereira Vieira, a visibilidade dos dejetos distanciou as senhoras de suas lembranças, ou aproximou-as daquele retrato, daquela recordação de quando o rio era limpo e suas águas potáveis. Diferentes relatos visuais e sensibilidades se apresentaram entre as gerações de lavadeiras, manifestando pelas fotografias que, dentre cores e formas, revelaram um outro tempo e um outro no tempo (Pesavento 2005). 
Enquanto no Pompéu, as senhoras observaram uma vívida mata ciliar, com menos degradação por despejo de dejetos e esgotos domésticos e industriais; no segundo, no centro da cidade, surgia o principal motivo de nossa atuação, já que se faz necessário uma “voz audível” de denúncia diante da rápida degradação da vegetação.

A maioria das participantes não possuía o hábito de usar câmeras, inclusive, nem as do celular. A intenção inicial era que elas mesmas fizessem seus registros fotográficos, mas houve um estranhamento diante da tecnologia, sendo que a maior parte delas preferiu chamar a atenção para aquilo que via e delegar a alguém a responsabilidade do registro, que poderia ser da monitora ou de alguma senhora que se sentisse mais confortável em fotografar, mas houve envolvimento diferente em outros grupos conforme relato de uma das monitoras: "Todas se sentiram muito à vontade em compartilhar entre si o que achavam pertinente fotografar ou não. A máquina fotográfica teve uma rotatividade razoável entre elas. Auxiliei, sobretudo, com o zoom e o enquadramento das fotos".

Nesse grupo, a dinâmica foi diversa, mas a produção continuou sendo coletiva como as outras. Pode-se afirmar que houve uma criação comunitária da atividade, porque quando uma delas destacava algo que chamava a atenção, isso vinha sempre acompanhado de uma história do porquê daquele despertar, que logo era acompanhado das observações das outras senhoras do grupo e um grande murmurinho. Surgia uma espécie de prosa visual. Em pouco tempo, os equipamentos que traziam receio e estranhamento foram incorporados a todo esse processo e elas mesmas pediam para ver "como a foto ficou" e sempre pontuavam como os tempos mudavam, porque "agora a gente até vê a foto na hora". E tudo aquilo era um grande celebrar de suas trajetórias e experiências. A riqueza dessa experiência visual coletiva trouxe reflexões principalmente em relação ao processo de interpretação imagético/mnemônico: temos a interpretação da memória apontada pelas próprias senhoras e a que será registrada imageticamente pelas monitoras. Pode-se questionar uma dupla interpretação a surgir dessa mediação, mas a partir do momento que se usa a fotografia como meio de criação há sempre a preocupação com o subjetivo. Fontcuberta afirma que "o potencial expressivo de qualquer fotografia se estratifica em diferentes graus de pertinência informativa" (2010:11). Durante as oficinas buscou-se guiar por essa "pertinência informativa" para se obter um entendimento sobre qual memória e emoções as senhoras falavam e buscavam registrar, mas sempre estivemos conscientes das características muito próprias que a fotografia apresenta.

É interessante observar que as fotografias produzidas configuram-se pelas memórias que tomaram contorno a partir de uma imensa produção imagética. Isso demostra que as imagens também são frutos de referências e vivências, emergindo de uma teia de significações (Geertz 1989) que constrói e (re)constrói olhares e sentidos diversos.

As oficinas de fotografias foram necessárias para [re] estabelecer as relações de afeto e vínculo com os trajetos, histórias e experiências diante das modificações e conservações do Rio Sabará. Suas produções urdiram narrativas por meio do registro fotográfico de locais de memória, criando mapas afetivos para a mediação de uma educação ambiental e patrimonial de coletividades. Ao entrelaçar tais vivências e experiências com o registro fotográfico, houve uma (re)construção de narrativas, um entrelaçamento entre passado-presente e uma ressignificação do próprio ofício. A fotografia não apenas ajudou a pensar sobre as novas tecnologias como forma de registro, mas também como uma recuperação da memória, do passado, pois pode "revelar" sentidos para além da aparente imagem visual. 


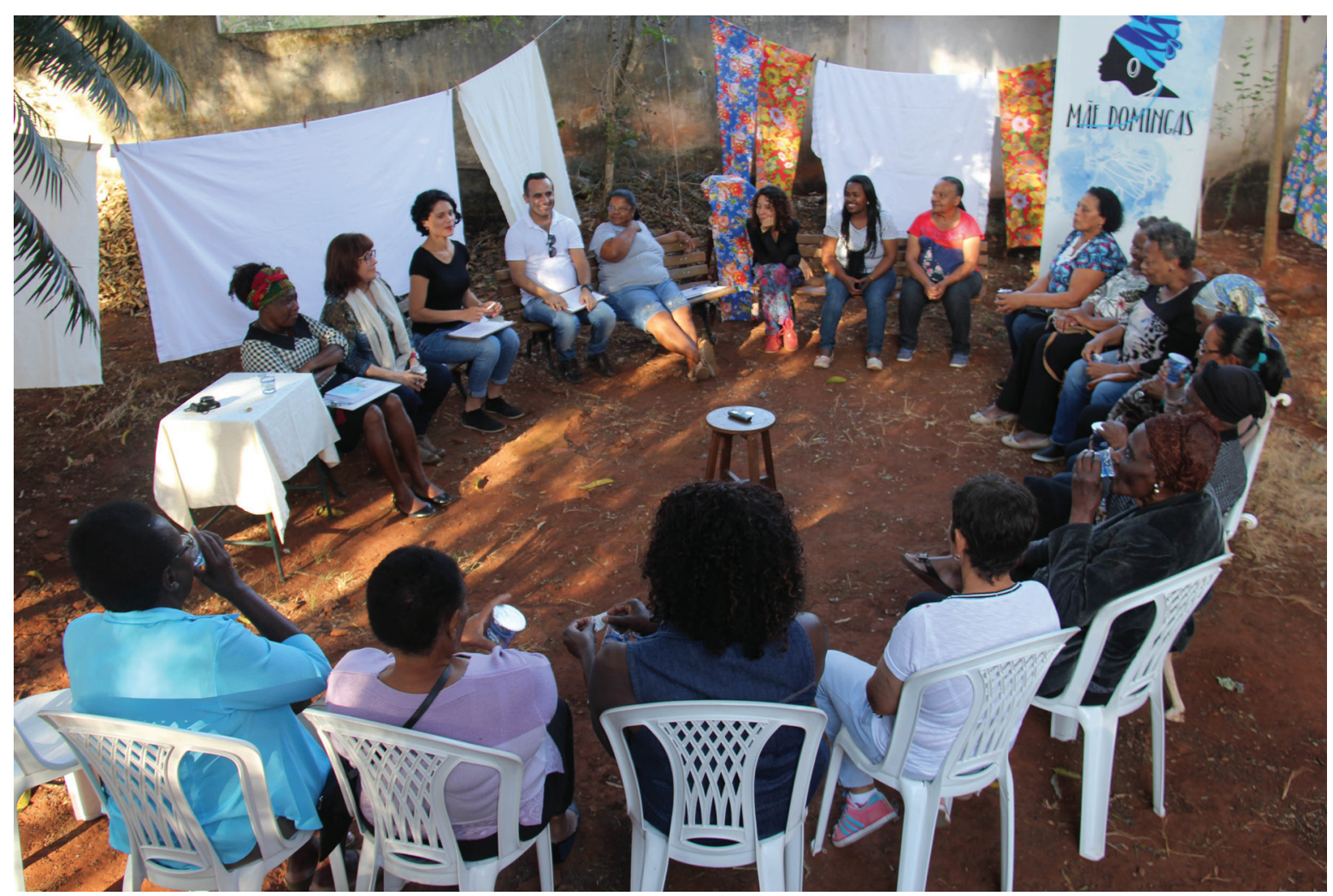

Fotografia 1: O projeto começou com uma roda de conversas no Museu do Ouro/Ibram. Centro - Sabará/MG.

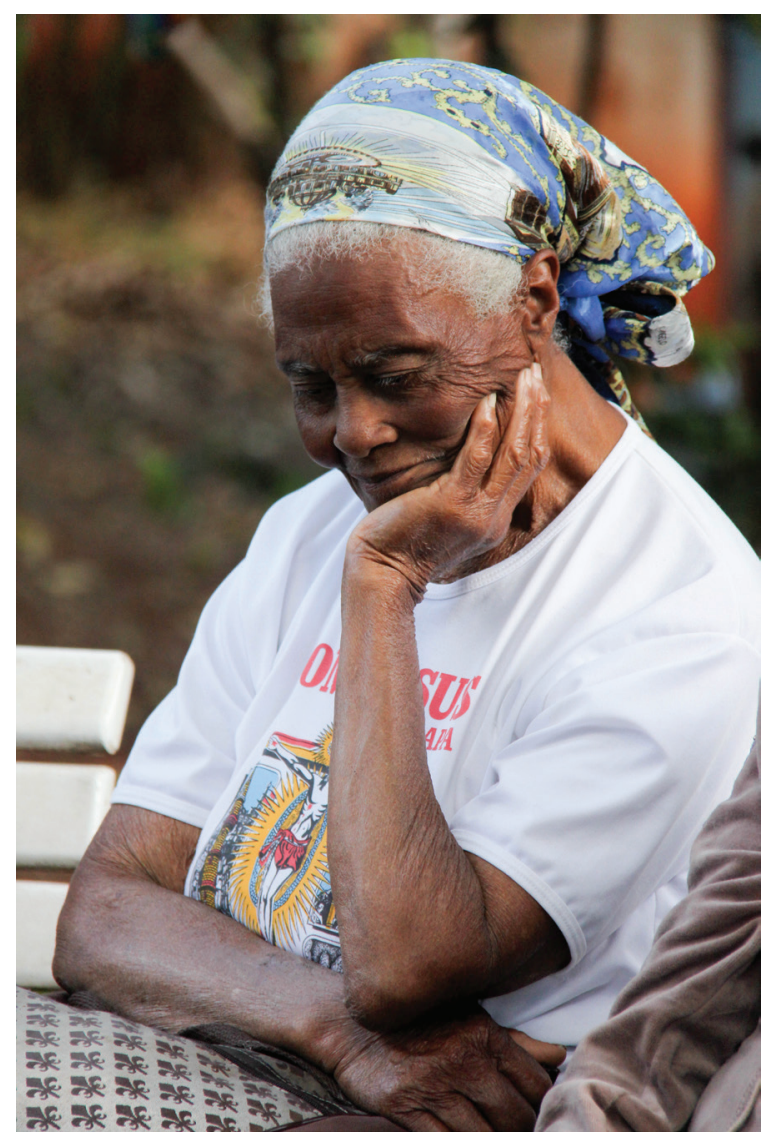

Fotografia 2: Dona Ana e as lembranças do rio. Museu do Ouro/Ibram. Centro - Sabará/MG.

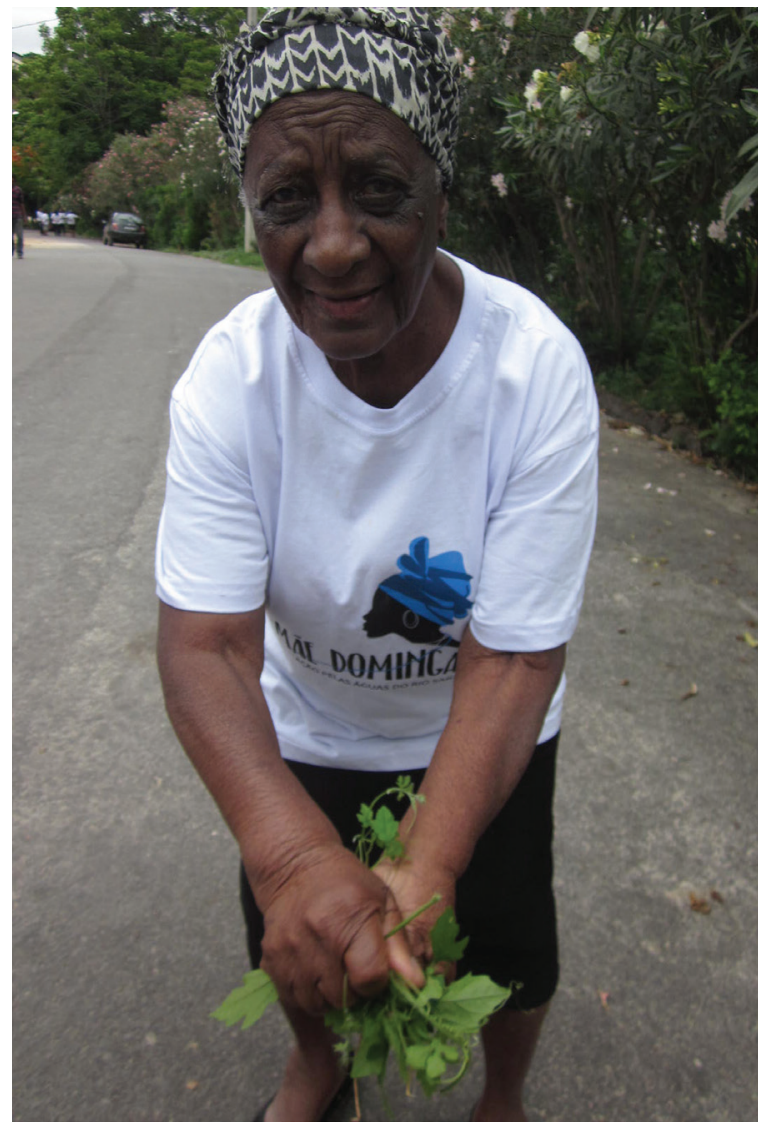

Fotografia 3: Dona Nilza, uma das ex-lavadeiras, mostra-nos sobre uso do "melão de São Caetano" para alvejar as roupas. Pereira Vieira - Centro - Sabará/MG. 


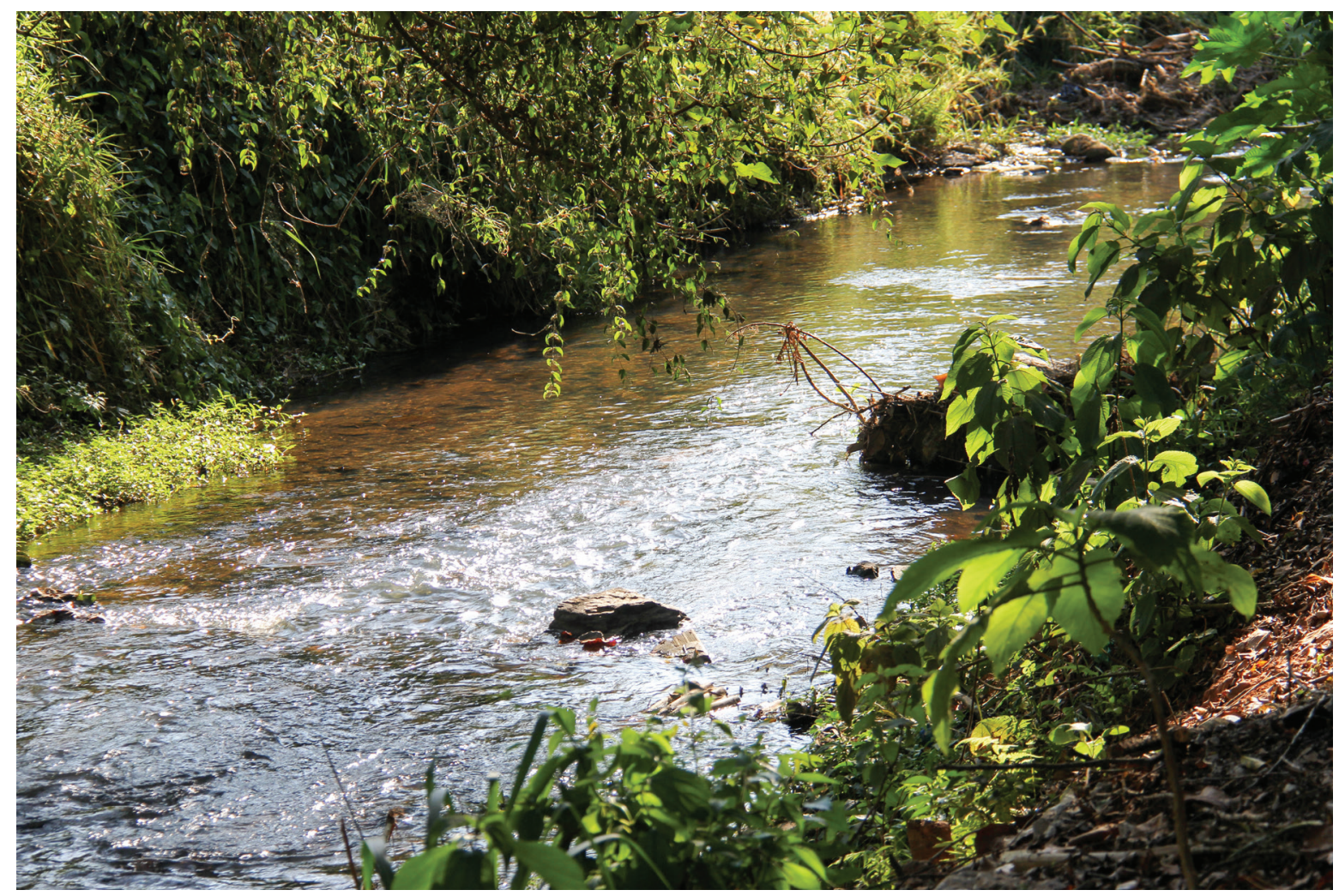

Fotografia 4: No Bairro Pompéu, as margens do Rio Sabará.

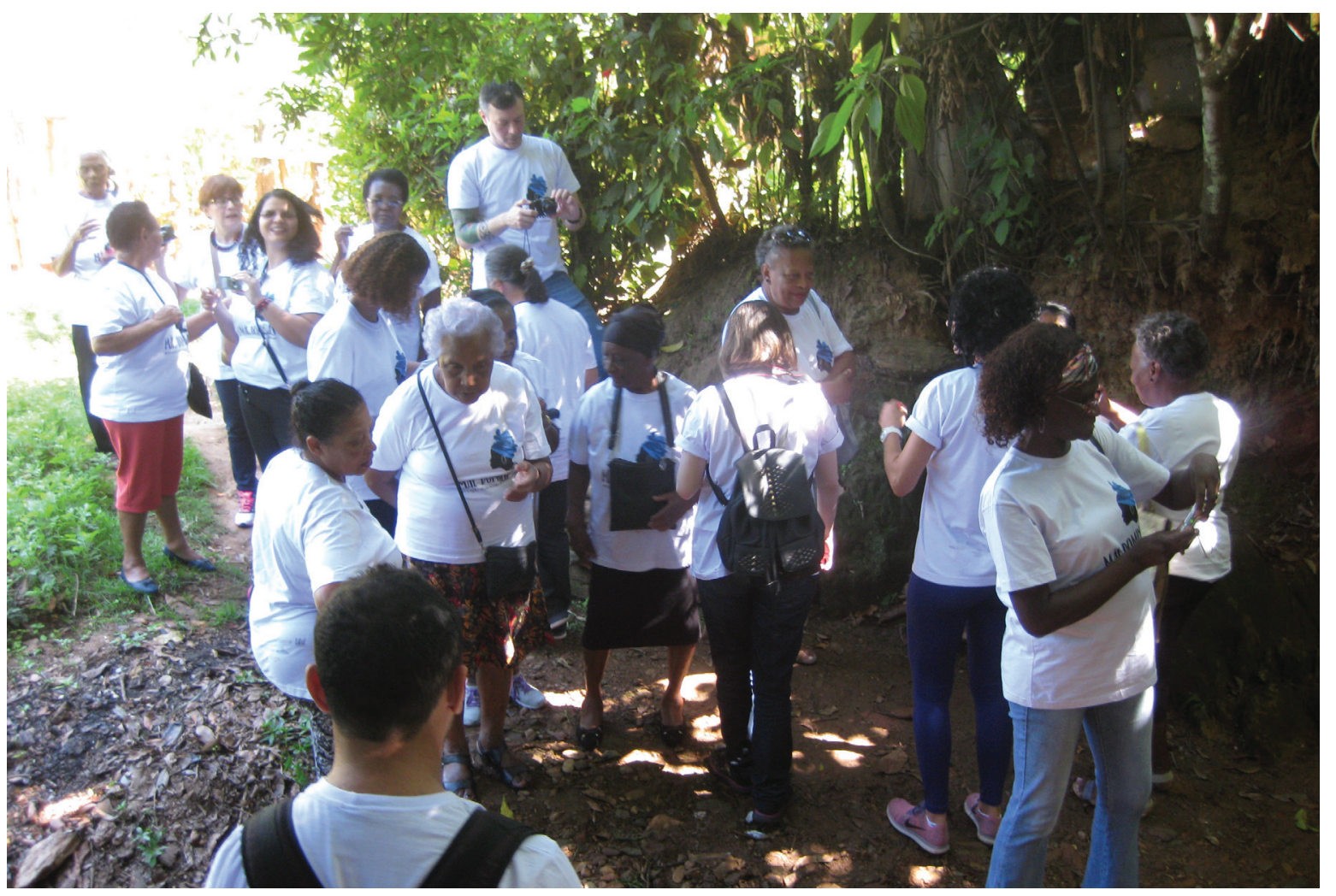

Fotografia 5: Na trilha, velhas bicas d'água refrescam a memória. Pompéu - Sabará/MG. 


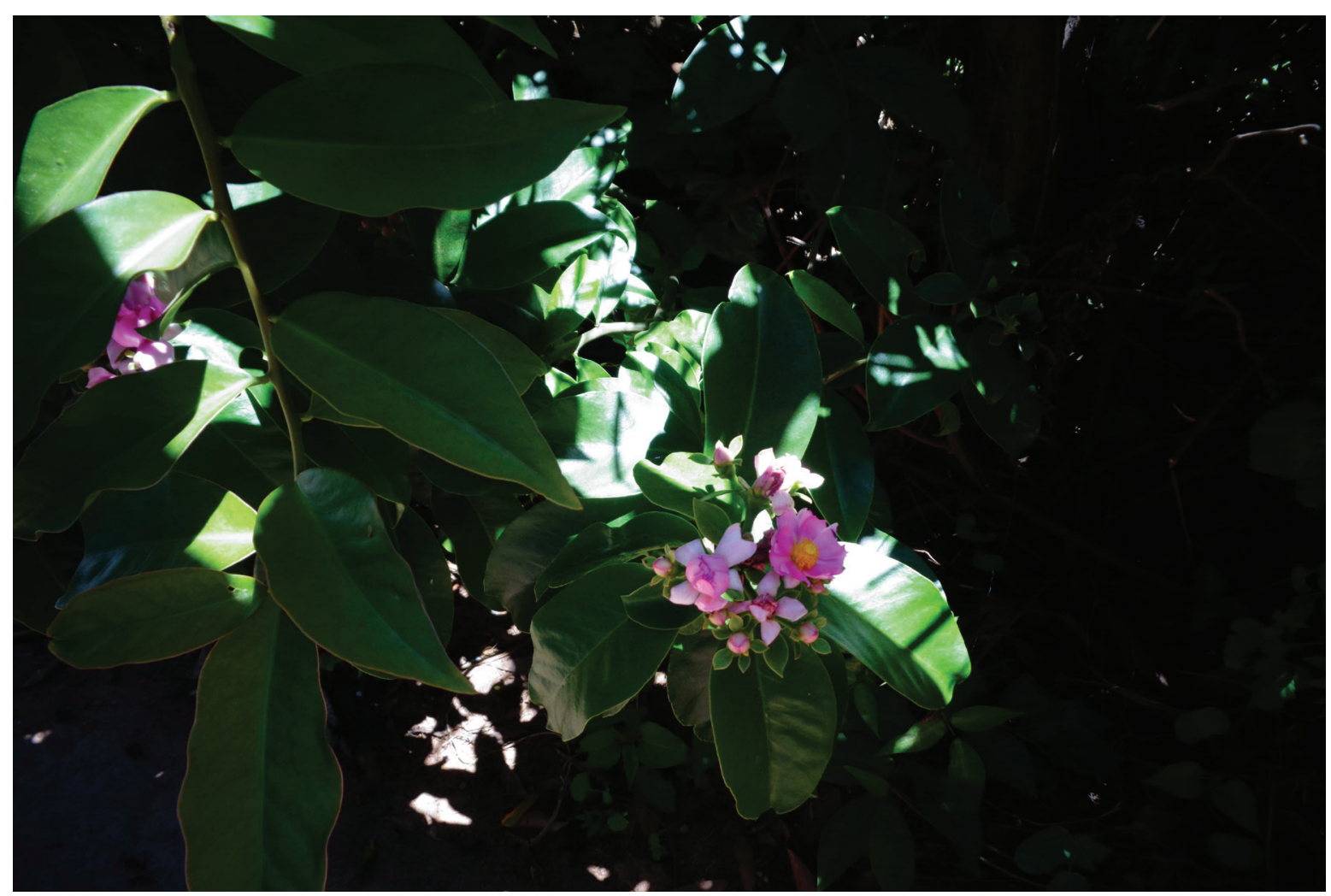

Fotografia 6: A flor do oropronobis. Registro feito pelas senhoras. Pompéu - Sabará/MG.

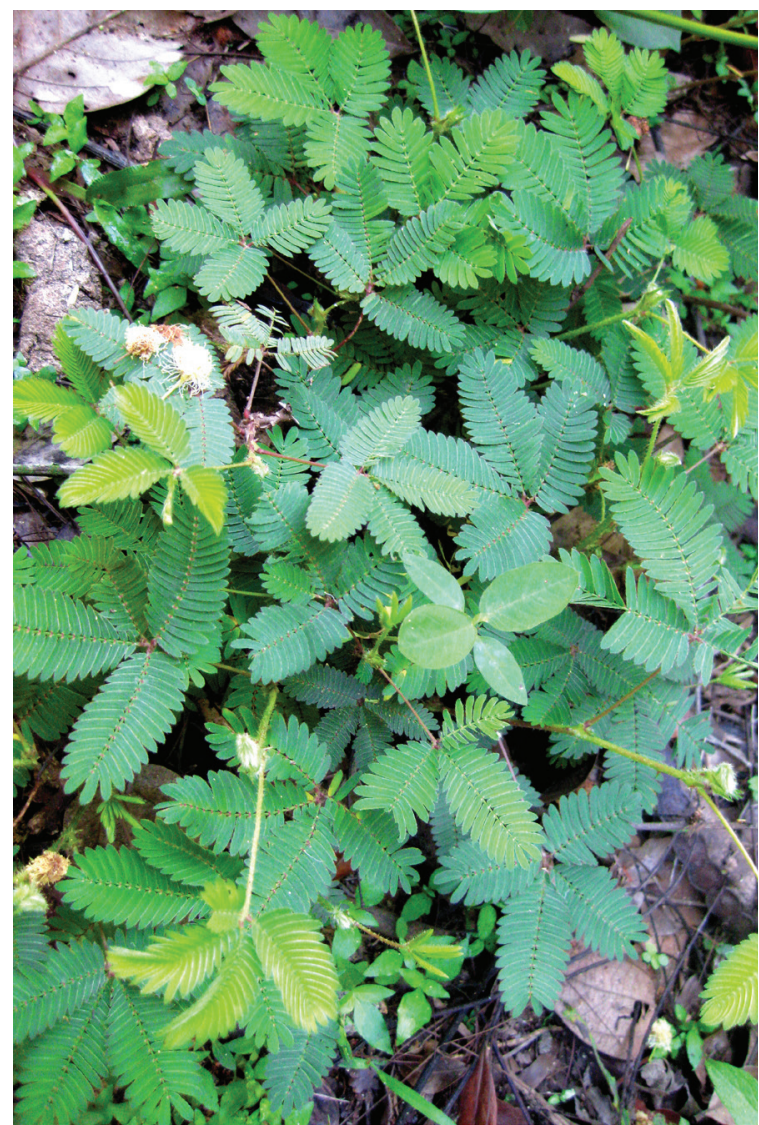

Fotografia 7: Maria, fecha a porta.

Registro feito pelas senhoras. Pompéu - Sabará/MG.

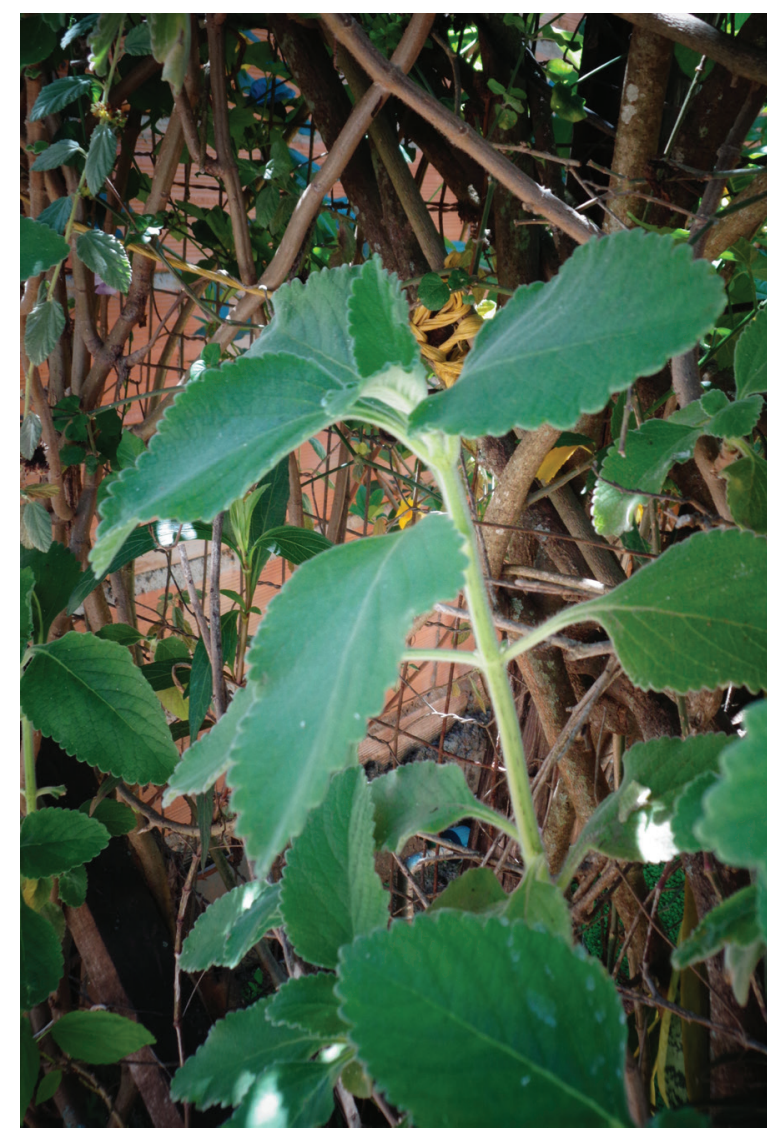

Fotografia 8: Nos caminhos, plantas e reminiscências. Registro feito pelas senhoras. Pompéu - Sabará/MG. 


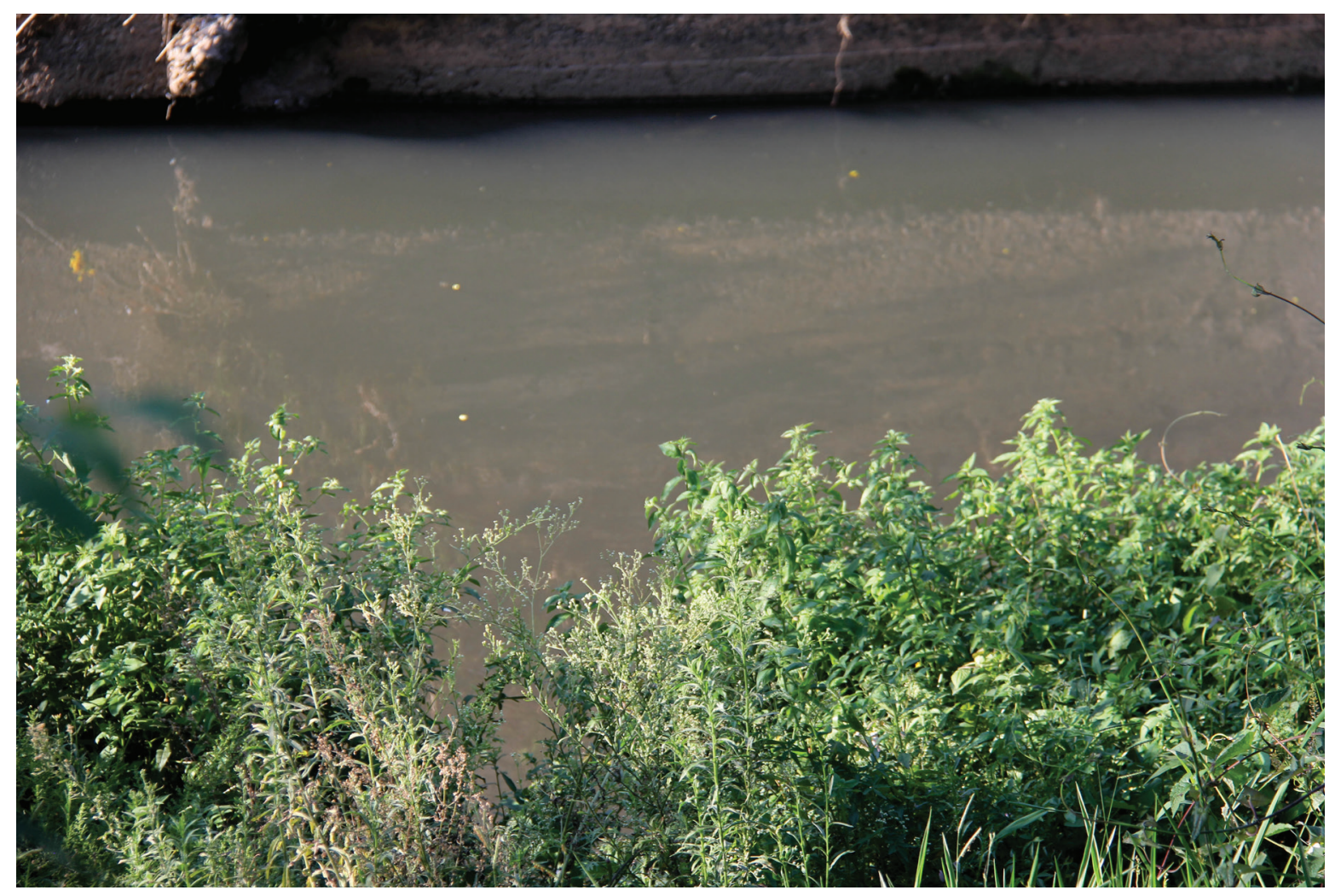

Fotografia 9: Ao centro da cidade, outro rio se mostra. Pereira Vieira - Centro - Sabará/MG.

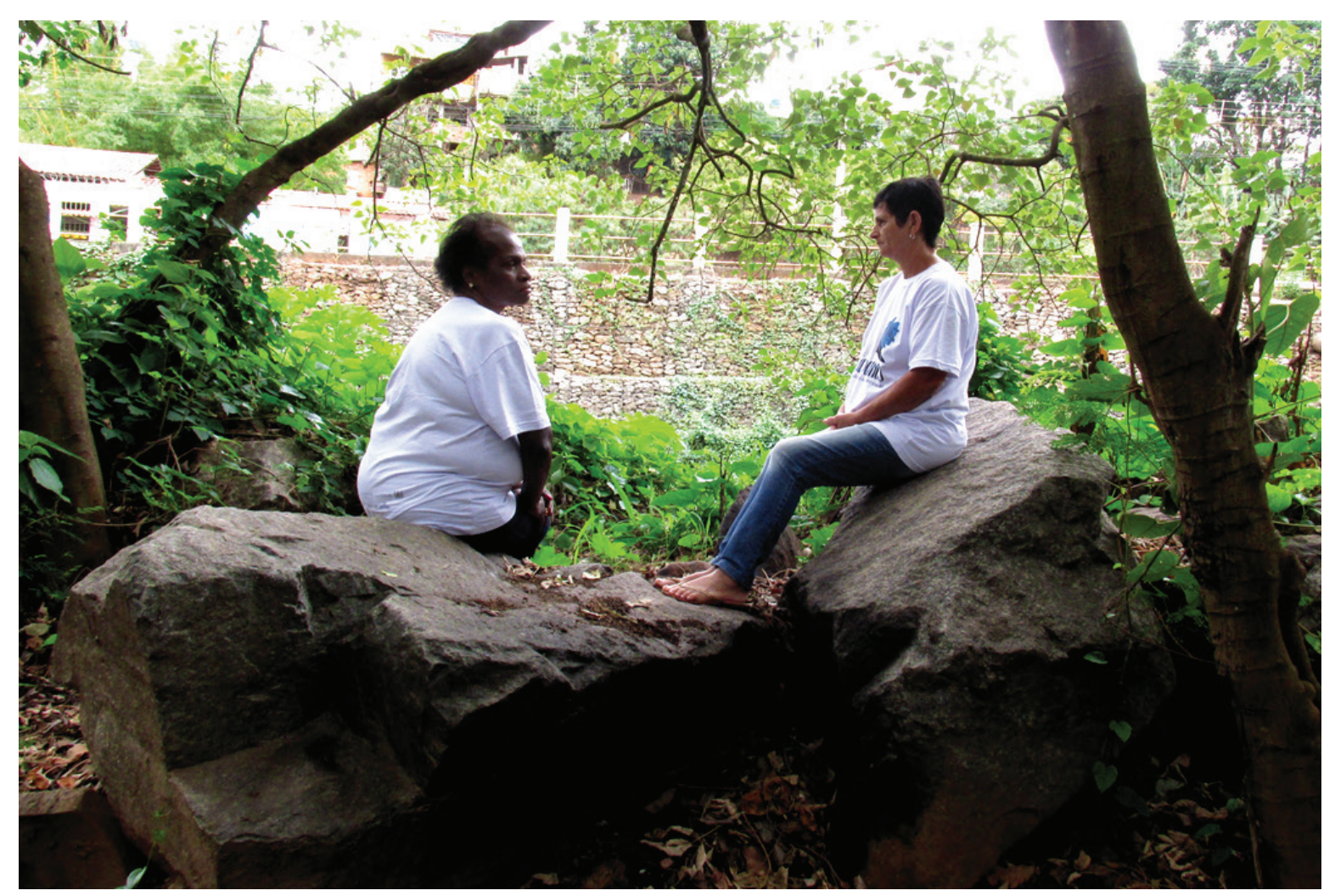

Fotografia 10: Tânia e Piedade recriam as brincadeiras de infância. Pereira Vieira - Centro - Sabará/MG. 
Frederico Luiz Moreira é doutorando em Antropologia Social pela Universidade Federal de Minas Gerais (UFMG).

Júnia Patricia Cardoso é Mestra em Educação pela Universidade Estadual de Minas Gerias (UEMG).

\section{REFERÊNCIAS BIBLIOGRÁFICAS}

BARROS, José Márcio P. de M. 1996. 2 ou 3 questôes sobre o olhar. Belo Horizonte. 2 f. Mimeografado. BITTENCOURT, Luciana A. 1998. "Algumas considerações sobre o uso da imagem fotográfica na pesquisa antropológica". In: Desafios da Imagem: Fotografia, iconografia e video nas ciências sociais, org. B. Feldman-Bianco e M. L. M. Leite. Campinas, SP: Papirus. CHARTIER, Roger. 1991. "O mundo como representação". Estudos Avançados 11(5). FONTCUBERTA, Joan. 2010. O beijo de Judas: Fotografia e verdade. Barcelona: GG. GEERTZ, Clifford. 1989. O impacto do conceito de cultura sobre o conceito de homem. In: A interpretação das culturas. Rio de Janeiro: LTC.

INGOLD, Tim. 2010. Da transmissão de representações à educação da atenção. Educação 33(1): 6-25. KOSSOY, Boris. 2014. Fotografia e história. 5. ed. São Paulo: Ateliê Editorial.

LE GOFF, Jacques. 1990. História e memória. Tradução Bernardo Leitão, et all. Campinas: UNICAMP.

NORA, P. 1993. Entre memória e história. A problemática dos lugares. Projeto História, São Paulo: PUC. n. 10. pp. 7-28.

PESAVENTO, Sandra J. 2005. Sensibilidades no tempo, tempo das sensibilidades. Nuevo Mundo Mundo Nuevos [En ligne], Colloques, mis em ligne le 04 février. Disponível em: <https://journals.openedition.org/nuevomundo/>. Acesso em: 27 de nov de 2015. 


\title{
CARTOGRAFiAS SENSÍVEIS NO E PELO RIO SABARÁ
}

Resumo: Este ensaio etnofotográfico apresenta uma proposta pedagógica utilizada como intervenção no projeto de pesquisa e extensão universitária, ganhador do prêmio do Edital PAEX No01/2017, "Mãe Domingas: educação pelas águas do Rio Sabará" desenvolvido na cidade de Sabará/MG, em parceria com as instituições: Faculdade de Educação - UEMG (Grupo de Pesquisas Polis e Mnemosine), Museu do Ouro/Ibram, Universidade Laval (Quebec/Canadá) e Escola de Ciência da Informação/ UFMG. No projeto foram realizados relatos fotográficos e reflexões sobre as memórias coletivas e individuais de ex-lavadeiras, a partir de duas oficinas de fotografias que [re] estabeleceram as relações de afeto e vínculo com trajetos, histórias e vivências diante das mudanças e permanências do Rio Sabará. As oficinas produzidas urdiram narrativas por meio do registro fotográfico de locais de memória criando mapas afetivos para a mediação de uma educação das sensibilidades e de patrimônios.

Palavras-chave: Fotografia; educação; patrimônio; memória; ambiente.

\section{SENSITIVE CARTOGRAPHIES IN AND THROUGHOUT SABARÁ RIVER}

\begin{abstract}
This ethnographic essay presents a pedagogical proposal used as an intervention in the academic research and extension project, prize winner of EDITAL PAEX No01/2017, "Mãe Domingas, educação pelas águas do Rio Sabará”, developed in the city of Sabará/MG in partnership with the following institutions: Faculty of Education - UEMG (Research Group Polis and Mnemosine), Museu do Ouro/Ibram, Laval University (Quebec/Canada) and School of Information Science/UFMG. In this project, photographic accounts and reflections on the collective and individual memories of former washerwomen were performed, these were made through two photography workshops that [re] established the relations of affection and bond with routes, stories, and experiences in the face of changes and permanence of Sabará River. These workshops wove narratives through photographic records of places of memory which created affection maps to mediate an education of sensibilities and patrimonies.
\end{abstract}

Keywords: Photography; education; patrimony; memory; ambient.

RECEBIDO: $22 / 04 / 2020$

APROVADO: $01 / 07 / 2020$ 